3. Craven LJ, Nair Parvathy S, Tat-Ko J, Burton JP, Silverman MS. Extended screening costs associated with selecting donors for fecal microbiota transplantation for treatment of metabolic syndrome-associated diseases. Open Forum Infect Dis 2017;4(4): of 243.

4. Costello SP, Tucker EC, La Brooy J, Schoeman MN, Andrews JM. Establishing a fecal microbiota transplant service for the treatment of Clostridium difficile infection. Clin Infect Dis 2016; 62:908-14.

5. Biedermann L, Zeitz J, Mwinyi J, et al. Smoking cessation induces profound changes in the composition of the intestinal microbiota in humans. PLoS One 2013;8(3):e59260.

DOI: 10.1056/NEJMc1913670

\title{
Ambient Air Pollution and Mortality in 652 Cities
}

TO THE EDITOR: In response to the article by Liu et al. (Aug. 22 issue) ${ }^{1}$ : the inhalable fraction of particulate matter with an aerodynamic diameter of $10 \mu \mathrm{m}$ or less $\left(\mathrm{PM}_{10}\right)$ in the real world is made up of a mixture of substances probably derived from many sources. ${ }^{2}$ In urban areas, a substan-

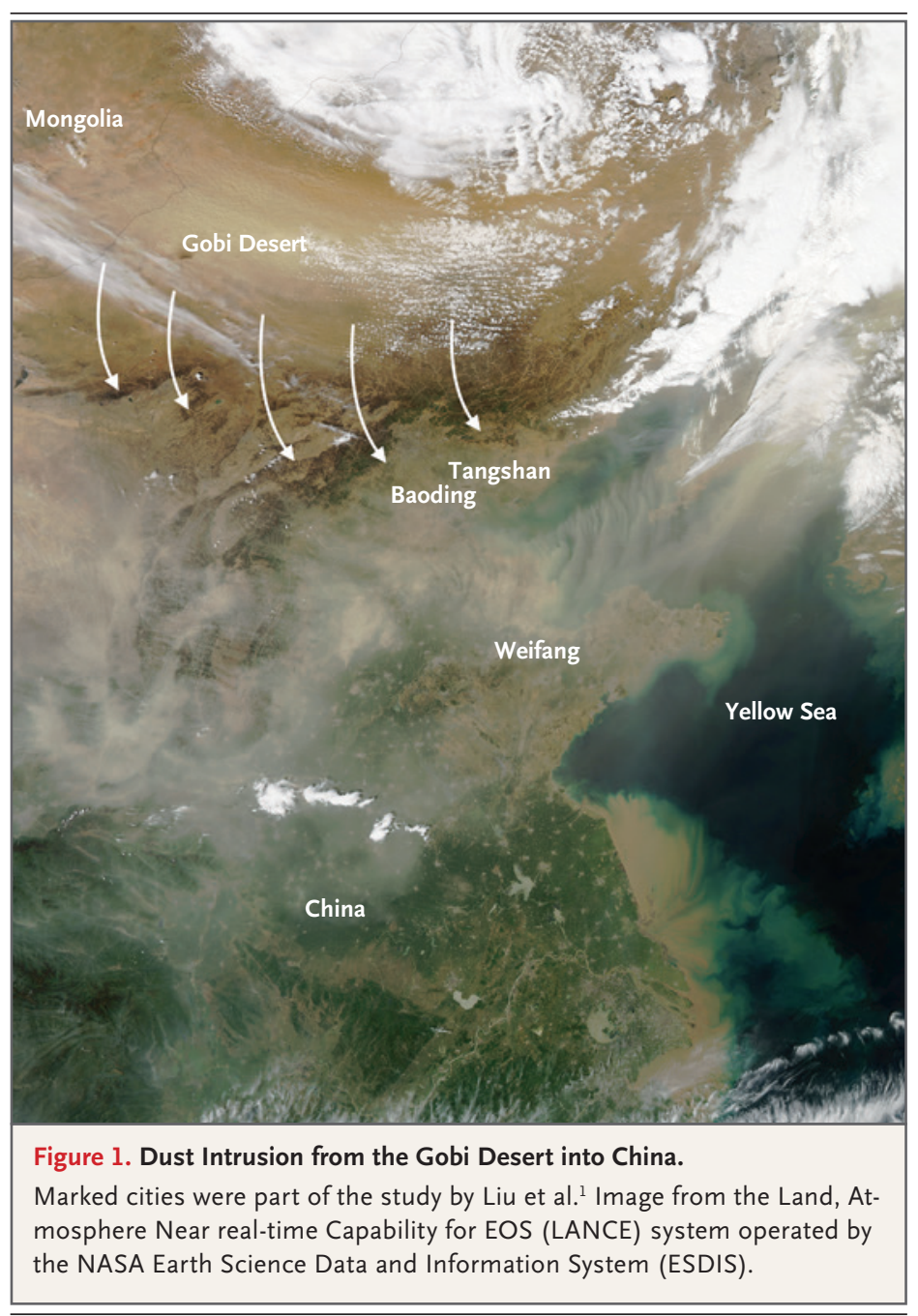

tial fraction of $\mathrm{PM}_{10}$ is related to combustion emissions (transport, industry, power generation, and the like). ${ }^{3}$ However, in arid regions, a large fraction of $\mathrm{PM}_{10}$ derives from desert dust particles. This kind of $\mathrm{PM}_{10}$, emitted from the soil of deserts and transported by the action of wind, causes dust storms that are common in North Africa, the Middle East, and inner Asia and that occur occasionally in Mediterranean countries and the North Atlantic. The global effect is poor air quality for more than 2 billion people. ${ }^{4}$

The influence of $\mathrm{PM}_{10}$ that is derived from combustion on cardiovascular pathophysiology is different from the influence of $\mathrm{PM}_{10}$ derived from dust. ${ }^{5}$ This differentiation should be considered in global studies that have included regions affected by desert dust, such as inner Asia (Fig. 1); studies need to be done to determine the causal components in particulate matter.

\section{Daniel Hernandez-Vaquero, M.D., Ph.D.}

Instituto de Investigación Sanitaria del Principado de Asturias Oviedo, Spain

dhvaquero@gmail.com

Sergio Rodriguez, Ph.D.

Estación Experimental de Zonas Áridas Almería, Spain

\section{Alberto Dominguez-Rodriguez, M.D., Ph.D.}

Hospital Universitario de Canarias

Tenerife, Spain

No potential conflict of interest relevant to this letter was reported.

1. Liu C, Chen R, Sera F, et al. Ambient particulate air pollution and daily mortality in 652 cities. N Engl J Med 2019;381:705-15. 2. Pope CA III, Dockery DW. Health effects of fine particulate air pollution: lines that connect. J Air Waste Manag Assoc 2006; 56:709-42.

3. Putaud J-P, Van Dingenen R, Alastuey A et al. A European aerosol phenomenology: physical and chemical characteristics of particulate matter from 60 rural, urban, and kerbside sites across Europe.Atmos Environ2010;44:1308-20. 
4. Engelstaedter S, Tegen I, Washington R. North African dust emissions and transport. Earth Sci Rev 2006;79:73-100.

5. De Longueville F, Hountondji YC, Henry S, Ozer P. What do we know about effects of desert dust on air quality and human health in West Africa compared to other regions? Sci Total Environ 2010;409:1-8.

DOI: 10.1056/NEJMc1913285

TO THE EDITOR: Liu et al. claim that poor air quality, due to increased particulate matter, in more than 600 cities across the world can be linked to mortality. We question the reliability of this claim given negative studies ${ }^{1,2}$ and reanalysis of two meta-analytic studies ${ }^{3,4}$ in which the reanalysis attempts to vitiate the conclusion of the source studies that particulate matter causes heart attacks. With respect to Liu et al., $16 \mathrm{P}$ values that we computed from data regarding fine particulate matter with an aerodynamic diameter of $2.5 \mu \mathrm{m}$ or less $\left(\mathrm{PM}_{2.5}\right)$ in Table 1 of their article lead to a striking P-value plot: 8 values along a roughly 45-degree line are consistent with the lack of a causal association, whereas 8 are less than 0.05 , supporting an association (Fig. 1). In effect, we think that Liu et al. reported data from studies that form a two-component mixture, as observed in two recent reports ${ }^{3,4}$; we think it makes no sense to report an average based on a mixture having two components.

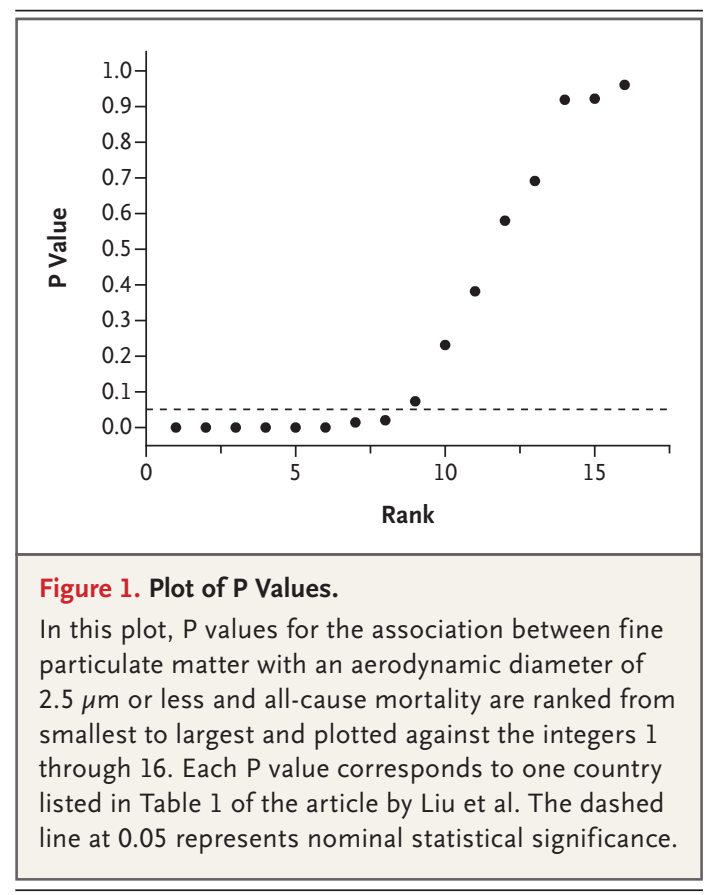

S. Stanley Young, Ph.D.

CGStat

Raleigh, NC

genetree@bellsouth.net

Warren Kindzierski, Ph.D.

University of Alberta

Edmonton, $A B$, Canada

No potential conflict of interest relevant to this letter was reported.

1. Milojevic A, Wilkinson P, Armstrong B, Bhaskaran K, Smeeth L, Hajat S. Short-term effects of air pollution on a range of cardiovascular events in England and Wales: case-crossover analysis of the MINAP database, hospital admissions and mortality. Heart 2014;100:1093-8.

2. Young SS, Smith RL, Lopiano KK. Air quality and acute deaths in California, 2000-2012. Regul Toxicol Pharmacol 2017; 88:173-84.

3. Young SS, Acharjee MK, Das K. The reliability of an environmental epidemiology meta-analysis, a case study. Regul Toxicol Pharmacol 2019;102:47-52.

4. Young SS, Kindzierski WB. Evaluation of a meta-analysis of air quality and heart attacks, a case study. Crit Rev Toxicol 2019; 49:85-94.

DOI: $10.1056 / N E J M c 1913285$

TO THE EDITOR: Liu et al. found consistent increases in daily all-cause, cardiovascular, and respiratory mortality in association with increasing concentrations of ambient particulate matter in 652 cities worldwide. We caution that future studies should not consider populations of individual cities as a static entity. Cities are increasingly connected, currently with 1.2 billion international arrivals per year. ${ }^{1}$ Cities, their residents, their visitors, and their temporary residents do not represent a constant cohort but present dynamic interdependent systems in concert with variable pollution profiles. The health effects that are observed in an individual's usual residence city might be more associated with exposures in a frequent destination city or temporary residence city. Even short-stay international travel to cities with elevated air pollution by healthy adults has now been associated with adverse cardiopulmonary health effects, including decreased lung function and heart-rate variability and an increase in respiratory symptoms. ${ }^{2}$ Future research should consider mobile sectors of the population when studying air pollution-related health outcomes. Municipal authorities should be responsible for the health of their residents and visitors. 
M.J. Ruzmyn Vilcassim, Ph.D.

University of Alabama at Birmingham School of Public Health Birmingham, AL

ruzmyn@uab.edu

David O. Freedman, M.D.

University of Alabama at Birmingham School of Medicine Birmingham, AL

Annelies Wilder-Smith, M.D., Ph.D.

Heidelberg Institute of Global Health

Heidelberg, Germany

No potential conflict of interest relevant to this letter was reported.

1. Glaesser D, Kester J, Paulose H, Alizadeh A, Valentin B. Global travel patterns: an overview. J Travel Med 2017;24(4):tax007.

2. Vilcassim MJR, Thurston GD, Chen LC, et al. Exposure to air pollution is associated with adverse cardiopulmonary health effects in international travellers. J Travel Med 2019;26(5):taz032.

DOI: 10.1056/NEJMc1913285

TO THE EDITOR: The editorial by Balmes ${ }^{1}$ regarding the 652-city study of air pollution by Liu et al. cites an article in Science ${ }^{2}$ that states that I want to rely on studies that use a theoretical approach called "manipulative causality" as the basis for regulatory decision making, thereby restricting epidemiologic evidence considered in assessing causality. Neither article correctly paraphrases my views. The Clean Air Scientific Advisory Committee recently asked for a "clearer discussion of causality." My personal view is that the weightof-evidence approach of the Environmental Protection Agency (EPA) does not offer a clear definition for causality in studies of air pollution. I think that the EPA should specifically characterize the types of harm to human health that are preventable or can be lessened by reducing exposures to particulate matter (manipulative causation), since this is ultimately what could matter most to policymakers. ${ }^{4}$ Balmes opines that this "would set a dangerous precedent for environmental policy." I seek clarity in the definition of causality in studies of air pollution, not restrictions on the evidence considered.

Louis A. Cox, Jr., Ph.D.

University of Colorado

Denver, $\mathrm{CO}$

tcoxdenver@aol.com

No potential conflict of interest relevant to this letter was reported.

1. Balmes JR. Do we really need another time-series study of the $\mathrm{PM}_{2.5}$-mortality association? N Engl J Med 2019;381:774-6.
2. Goldman GT, Dominici F. Don't abandon evidence and process on air pollution policy. Science 2019;363:1398-400.

3. Cox LA Jr. Letter to Honorable Andrew R. Wheeler regarding CASAC review of the EPA's integrated science assessment for particulate matter (external review draft - October 2018). April 2019 (https://yosemite.epa.gov/sab/sabproduct.nsf/LookupWeb ReportsLastMonthCASAC/6CBCBBC3025E13B4852583D90047B 352/\%24File/EPA-CASAC-19-002+.pdf).

4. Burns J, Boogaard $\mathrm{H}$, Polus $\mathrm{S}$, et al. Interventions to reduce ambient particulate matter air pollution and their effect on health. Cochrane Database Syst Rev 2019;5:CD010919.

DOI: 10.1056/NEJMc1913285

THE AUthors REPLY: Hernandez-Vaquero et al. raise a point regarding the identification of the causal components for mortality within inhalable particulate matter. We agree that the toxicity of particulate matter may vary with respect to different sources (such as combustion emissions and desert dust), and the composition of particulate matter is a potential source of heterogeneity in our study. More data are needed to expand our understanding of this link in inner Asia or the Middle East, where desert dust is the main contributor to inhalable particulate matter.

The comments by Young and Kindziersky are based on a biased summary of the literature and a misunderstanding of the study design that we used. First, the link between exposure to particulate matter and a short-term increase in mortality is firmly established from dozens of largescale, multicenter epidemiologic investigations and reports worldwide. ${ }^{1-3}$ This evidence cannot be dismissed by two small studies that assessed only cardiovascular events or were conducted in limited locations. More important, the authors did not acknowledge that our study is not a metaanalysis, but a multilocation study with direct data collection in 652 cities. The risks that we report in Table 1 of our article therefore do not represent previously published estimates, but countryspecific effects pooled from multiple cities directly measured with the use of a two-stage design. Thus, none of their arguments related to publication bias, "P-hacking," and subpopulations actually applies. Finally, the fact that some P values are above the significance threshold is expected, given the uncertainty of single estimates inherent in multicenter studies or related to the small data sets available from some regions. Our pooled estimates, however, indicate strong evidence of an association, with values that are consistent with those of most previous studies. 
Vilcassim et al. raise an issue of uncertainty from traveling or migration and proposed to pay attention to the health effects of air pollution among the mobile sector of the population. However, few natural deaths are expected to occur among active travelers; we cannot account for in-migration or out-migration, but the numbers are probably small compared with deaths in the resident population.

Cong Liu, M.S.

School of Public Health, Fudan University

Shanghai, China

Antonio Gasparrini, Ph.D.

London School of Hygiene and Tropical Medicine

London, United Kingdom

Haidong Kan, Ph.D.

School of Public Health, Fudan University

Shanghai, China

kanh@fudan.edu.cn

Since publication of their article, the authors report no further potential conflict of interest.

1. Romieu I, Gouveia N, Cifuentes LA, et al. Multicity study of air pollution and mortality in Latin America (the ESCALA study). Res Rep Health Eff Inst 2012;171:5-86.

2. Samoli E, Peng R, Ramsay T, et al. Acute effects of ambient particulate matter on mortality in Europe and North America: results from the APHENA study. Environ Health Perspect 2008; 116:1480-6.

3. Samet JM, Zeger SL, Dominici F, et al. The National Morbidity, Mortality, and Air Pollution Study. II. Morbidity and mortality from air pollution in the United States. Res Rep Health Eff Inst 2000;94:5-79.

DOI: 10.1056/NEJMc1913285

THE EDITORIALIST REPLIES: Cox expounds that the weight-of-evidence approach of the EPA does not offer a clear definition for causality; I disagree. The previously established approach of the EPA combines evidence from epidemiologic studies, human experimental studies, and toxicologic studies in animals to causally link exposure to an environmental hazard and a health outcome. Although Cox favors studies that involve manipulative causation, these are not feasible in largescale, multi-city studies of air pollution. In such settings, the Bradford Hill guidelines for inference of causation from observational studies are standard. ${ }^{1}$ These guidelines include strength of association, consistency, specificity, temporality, biologic gradient, plausibility, coherence, experimental evidence, and analogy. Although the evidence for the $\mathrm{PM}_{2.5}$-mortality association meets all of these guidelines, Cox does not accept them. ${ }^{2,3}$ The proven weight-of-evidence approach of the EPA is explicitly based on the Bradford Hill guidelines, which were used to establish the link between smoking and lung cancer, and is endorsed by the American Thoracic and European Respiratory Societies and the National Research Council. 4,5 We should not discard this time-tested approach to abet Cox's efforts to obfuscate our knowledge that $\mathrm{PM}_{2.5}$ can cause death.

John R. Balmes, M.D.

University of California, San Francisco

San Francisco, CA

Since publication of his editorial, the author reports no further potential conflict of interest.

1. Hill $\mathrm{AB}$. The environment and disease: association or causation? Proc R Soc Med 1965;58:295-300.

2. Integrated Science Assessment (ISA) for Particulate Matter (external review draft). Research Triangle Park, NC: Environmental Protection Agency, October 2018 (https://cfpub.epa.gov/ ncea/isa/recordisplay.cfm?deid=341593).

3. Goldman GT, Dominici F. Don't abandon evidence and process on air pollution policy. Science 2019;363:1398-400.

4. Thurston GD, Kipen H, Annesi-Maesano I, et al. A joint ERS/ ATS policy statement: what constitutes an adverse health effect of air pollution? An analytical framework. Eur Respir J 2017;49: 1600419.

5. Evidence integration for hazard identification. In: Committee to Review the IRIS Process, Board on Environmental Studies and Toxicology, Division on Earth and Life Studies. Review of EPA's Integrated Risk Information System (IRIS) process. Washington, DC: National Academies Press, 2014.

DOI: 10.1056/NEJMc1913285

\section{Oral Semaglutide and Cardiovascular Outcomes in Type 2 Diabetes}

TO THE EDITOR: Preventive strategies for cardiovascular complications in type 2 diabetes mellitus are essential. Subcutaneous glucagon-like peptide-1 (GLP-1) receptor agonists have signifi- cantly reduced cardiovascular risk in four of six published outcome trials. ${ }^{1,2}$ In the Peptide Innovation for Early Diabetes Treatment (PIONEER) 6 trial (Aug. 29 issue), ${ }^{3}$ the first oral GLP-1 receptor 